\title{
Обзорно-аналитическая информация
}

УДК: 69.001.12/.18:72:624.074.4

\section{К ВОПРОСУ О ПРИМЕНЕНИИ ПАРАБОЛИЧЕСКИХ ОБОЛОЧЕК ВРАЩЕНИЯ В СТРОИТЕЛЬСТВЕ В 2000-2017 ГОДАХ}

С.Н. КРИВОШАПКО, д-р техн. наук, профессор

Российский университет дружбы народов,

117198, Москва, ул. Миклухо-Маклая, д. 6,

sn_krivoshapko@mail.ru

Купол часто используется архитекторами для перекрытия больших пролетов. Среди десятков известных поверхностей вращения, которые можно приять за срединные поверхности куполов, находят применение сферические, конические, эллиптические, параболические и гиперболические поверхности вращения. Наибольшее распространение в современном строчтельстве получили сферические купола благодаря простоте их формы в сравнении с другими оболочками двоякой кривизньл. Однако не прекращаются исследования и параболоидов вращения. Некоторые новые сведения по расчету параболических оболочек на прочность, определению их частот собственных колебаний и примеры применения параболоидов вращения в строительстве в 1900-2017 годах приводятся в этой обзорной статье.

Вся основная приведенная библиография датируется XXI веком.

КЛЮЧЕВЫЕ СЛОВА: параболоид вращения, параболический купол вращения, примеры применения параболоида вращения.

Поверхность параболоида вращения образовывается вращением параболы $x^{2}=2 p z$ вокруг оси $z$ (рис. 1). Параболическую поверхность можно также получить движением подвижной параболы $y^{2}=2 p z$ вдоль неподвижной $x^{2}=2 p z$ (рис.

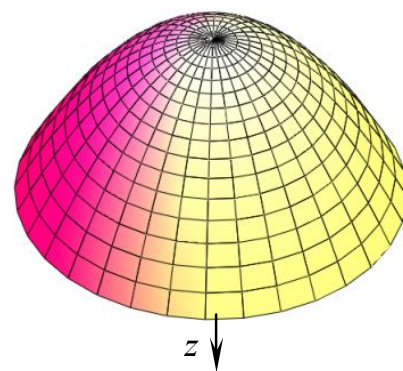

Рис. 1.

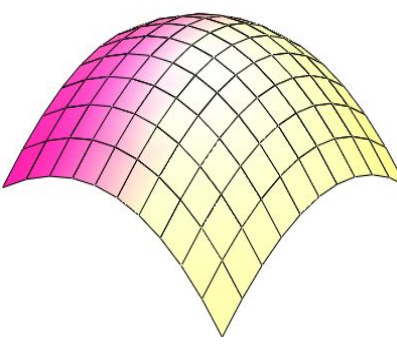

Рис. 2. 2). При этом необходимо, чтобы вершина подвижной параболы скользила по неподвижной, а плоскость и ось подвижной параболы оставались параллельными. Обе параболы должны быть обращены вогнутостью в одну сторону.

Параболоид вращения обладает оптическим свой-

ством: световые лучи, исходящие из фокуса, после зеркального отражения от поверхности параболоида пойдут параллельно оси параболоида вращения.

Явная форма задания (рис. 2): $2 z=\left(x^{2}+y^{2}\right) / p$.

Координатные линии $x, y$ на поверхности параболоида вращения (рис. 2) образуют чебышевскую сеть, т.е. у любого четырехугольника, образуемого линиями криволинейной координатной сети, противоположные стороны равны. Координатная сеть - неортогональна $(F \neq 0)$, но сопряженная $(M=0)$.

Параболоид вращения можно задать при помощи параметрических уравнений (рис. 1):

$$
x=x(r, \beta)=r \cos \beta, y=y(r, \beta)=r \sin \beta, z=z(r)=r^{2} /(2 p)
$$

или (рис. 1):

$$
x=x(u, v)=a \sqrt{u / h} \cos v, y=y(u, v)=a \sqrt{u / h} \sin v, z=z(u)=u ;
$$

где $u \geq 0 ; 0 \leq v \leq 2 \pi$. 
На высоте $z=h$ параболоид имеет радиус $r=a$. Площадь боковой поверхности параболоида вращения [1]:

его объем

$$
S=\pi a\left[\left(a^{2}+4 h^{2}\right)^{3 / 2}-a^{3}\right] /\left(6 h^{2}\right),
$$

$$
V=\pi a^{2} h / 2, \text { если } 0 \leq v \leq 2 \pi, \quad 0 \leq u \leq h .
$$

Явная форма задания эллиптического параболоида: $x^{2} / p+y^{2} / q=2 z$ где $p, q>0$. Следовательно, при $p=q$ эллиптический параболоид вырождается в параболоид вращения, т.е. параболоид вращения - частный случай эллиптического параболоида [2].

Поверхности 2-го порядка, в том числе и параболоиды вращения, с геометрической точки изучены очень хорошо. Однако в некоторых статьях встречается путаница в геометрических определениях и названиях. Например, в работе [3] отмечается: «В качестве объекта исследования был выбран железобетонный эллипсоидный купол, который в свою очередь имеет настоящий прототип в России. Реальный пример в нашей стране - Московский планетарий (1929 г. постройки). Один из самых больших в мире и самый старый планетарий в России. Размеры в плане этого здания идентичны смоделированным, отметки высот имеют незначительные различия с моделью. Выбор данного типа купола аргументирован тем, что данная геометрическая форма является наряду со сферической наиболее энергоёмкой и эффективной.». Но хорошо известно, что железобетонный купол Московского планетария имеет форму параболоида вращения. Не смотря на то, что в статье [3] нет уравнения срединной поверхности рассматриваемого купола, очевидно, что здесь тоже изучается параболоид враще-

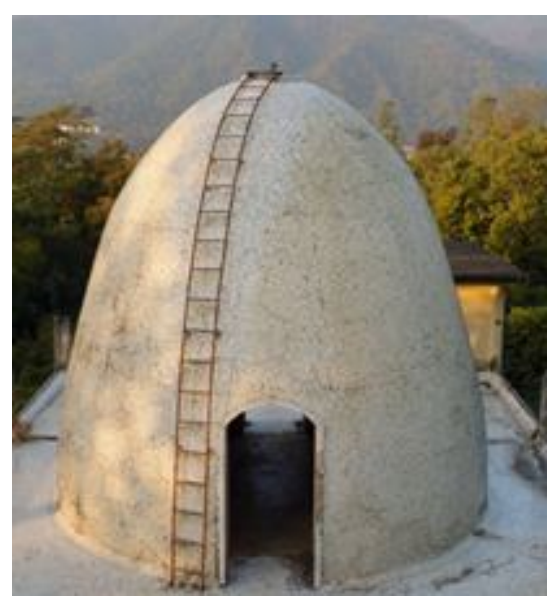

Рис. 3. «Параболический» купол ния.

Описывая одно из сооружений Ришикеш (Индия) в Livejournal, автор сообщения пишет: «Встав в центре, вы окажетесь почти в фокусе параболического отражателя, форму которого имеет яйцо» (рис. 3). Однако это сооружение в форме поверхности вращения не может быть параболоидом вращения, т.к. образующая кривая - не парабола, потому что имеет вертикальную касательную к меридиану на опоре, параллельную оси вращения.

Часто авторы статей по архитектуре не называют точно форму поверхности вращения, которая была выбрана за срединную поверхность оболочки, а ограничиваются только словом «купол». Но ведь купол вращения может быть параболическим, гиперболическим, фрагментом сферы или эллипсоида и т.д. [1]. Иногда внешне бывает трудно определить выбранную за основу поверхность вращения.

В.В. Новожилов [4] показал, что с точки зрения величины напряжений наиболее выгоден параболический купол, однако он требует наибольшей площади распорного кольца и с этой точки зрения наименее выгоден. Параболический купол вращения не имеет шва перехода и заставить работать его по безмоментной теории нельзя.

Чтобы уменьшить изгибные напряжения в куполе и уменьшить площадь поперечного сечения распорного кольца, инженеры предложили верхнюю часть 
купола делать в форме параболоида вращения, а нижнюю часть - каплевидную (рис. 4), взяв за аналог древние Византийские купола.

Применение пологих куполов дает существенное уменьшение неэксплуа-

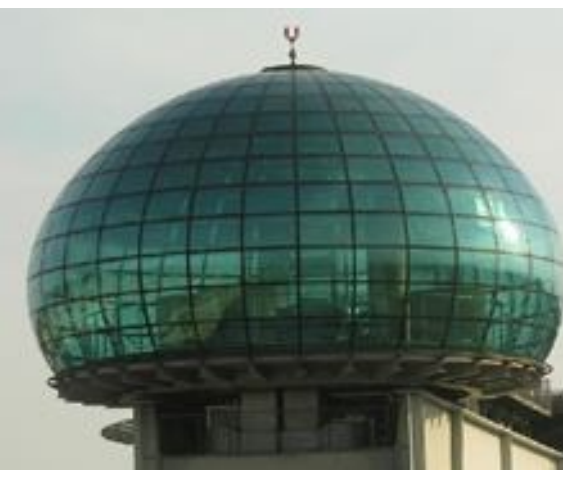

Рис. 4. [5] Комбинированный купол тируемого подкупольного пространства и минимальное отношение поверхности покрытия, приведенной к единице площади перекрываемого зала [9]. Уменьшению стрелы подъема купола сопутствует увеличение горизонтальной составляющей (распора) опорных реакций конструкции.

В наше время остро стоит вопрос защиты сооружений от террористической угрозы взрыва и здесь важную роль играет форма купола. В статье [7] изучается влияние избыточного внутреннего давления от взрыва на шесть видов куполов. Установлено, что параболический купол лучше всего выдерживает деформацию от взрыва (рис. 5).
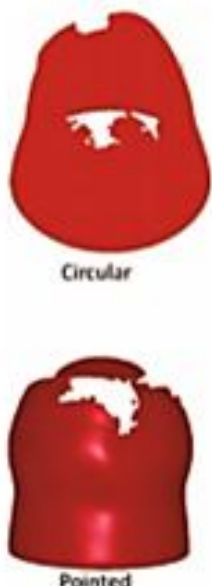
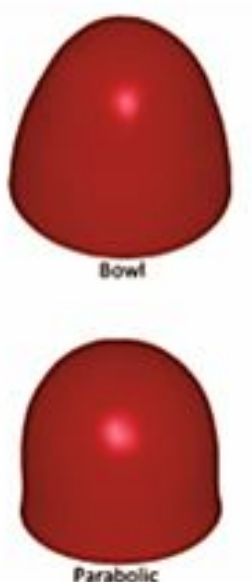
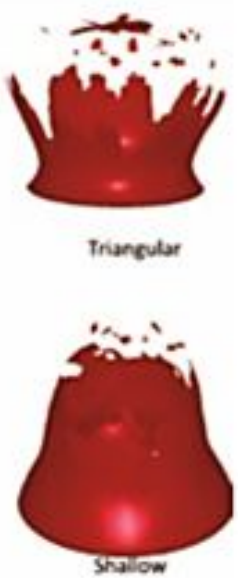

Рис. 5. Деформации куполов при взрывном избыточном давлении

Наиболее полный обзор по геометрии, расчету на прочность и устойчивость, на собственные и вынужденные колебания, по использованию параболоидов вращения в строительстве и архитектуре приведен в статье [8] с 63 названиями использованной литературы. Однако в этой статье приведено очень мало примеров использования параболоидов вращения в архитектуре и строительстве, перечислены только объекты, приведенные в табл. 1.

Таблича 1

\begin{tabular}{|l|l|l|l|l|}
\hline Название & \multicolumn{1}{|c|}{ Город } & Страна & Авторы & Построен в \\
\hline $\begin{array}{l}\text { Внешний купол Исаакиевского } \\
\text { собора }\end{array}$ & С.-Петербрг & Россия & & $1818-1858 г г$. \\
\hline $\begin{array}{l}\text { Стеклянный купол Педагогиче- } \\
\text { ского музея }\end{array}$ & Киев & Россия & & $1909-1912$ гг. \\
\hline $\begin{array}{l}\text { Жел.-бет. купол Московского } \\
\text { планетария }\end{array}$ & Москва & Россия & $\begin{array}{l}\text { М.Барщ, } \\
\text { М. Синявский }\end{array}$ & $1927-1929$ гг. \\
\hline $\begin{array}{l}\text { Склад концентратов металлурги- } \\
\text { ческого завода }\end{array}$ & Череповецк & Россия & $\begin{array}{l}\text { М. Туполев, А. } \\
\text { Попов, С. Иванов }\end{array}$ & 1960 г. \\
\hline
\end{tabular}

В табл. 2 приведены дополнительные примеры куполов в форме параболоидов вращения, построенных XX веке. 
Structural Mechanics of Engineering Constructions and Buildings, 2017, № 4

\begin{tabular}{|c|c|c|c|c|}
\hline \multicolumn{5}{|c|}{ Таблийа 2} \\
\hline Название & Город & Страна & Авторы & Построен в \\
\hline Первая Христианская церковь & $\begin{array}{l}\text { Оклахома- } \\
\text { Сити }\end{array}$ & США & $\begin{array}{l}\text { Р. Коннор, } \\
\text { Ф. Сюлливэн }\end{array}$ & $\begin{array}{l}\text { декабрь } \\
1956\end{array}$ \\
\hline Планетарий & Бохум & ФРГ & $\begin{array}{c}\text { Городское планировоч- } \\
\text { ное управление и Про- } \\
\text { ектное бюро Рамма }\end{array}$ & 1964 г. \\
\hline $\begin{array}{l}\text { The Integratron (полностью } \\
\text { деревянный купол) }\end{array}$ & Landers & США & G. Von Tassel & 1954 г. \\
\hline The Bahá'i House of Worship & Panama City & Panama & & 1972 г. \\
\hline «The King Dome» & Сиэтл & США & & $\begin{array}{l}1976-2000 \\
\Gamma г .\end{array}$ \\
\hline The Bahá'i House of Worship & Tiapapata & Samoa & H. Amanai & 1984 г. \\
\hline
\end{tabular}

Восполним этот пробел, обратив особое внимание на реальные примеры применения параболоида вращения, в основном, за последние 20 лет.

Эта поверхность привлекла внимание еще старинных строителей, например, параболический купол собора Св. Петра в Риме положил начало целой серии аналогичных сооружений. Считается, что купол возник в странах Востока и имел, прежде всего, утилитарное назначение. При отсутствии дерева покрытием для жилищ служили глиняные и кирпичные купола. Но постепенно, благодаря своим исключительным эстетическим и тектоническим качествам, купол приобрел самостоятельное смысловое содержание как архитектурная форма. Попрежнему купола находятся в поле зрения арабских архитекторов. Например, различные типы железобетонных куполов (сферические, эллипсоидальные и параболические) используются в нескольких зданиях университетского городка

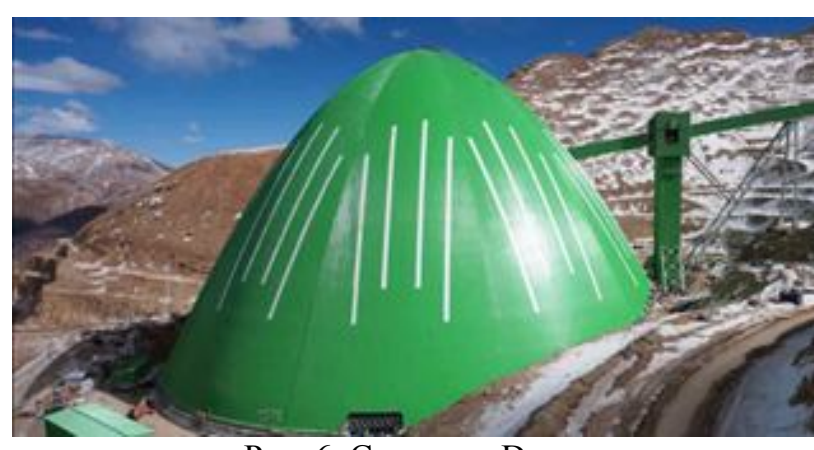

Рис. 6. Caserones Dome Американского университета в Шарджах (Sharjah, UAE), Объединенные Арабские Эмираты. Толщина, пролет и высота этих куполов разные в разных зданиях. Параболическая оболочка с фиксированными пролетом $(L=2 \times 13,7$ м) и высотой $(H=13,7$ м) и переменной толщиной $(0,05-$ 1,0 м) и параболическая оболочка с фиксированной толщиной $(t=0.2$ м) были изучены в работе [9], где авторы ссылаются на материалы статьи [10].

Классическая форма параболоида вращения применена для купола диаметром 145 м и высотой 94 м (Caserones Dome), построенного на высоте 4000 м над уровнем моря в Чилийских Андах (the Chilean Andes). Это самый большой купол в Южной Америке (рис. 6). Этот сетчатый купол из гальванизированной стали и алюминия хорошо выдерживает ветровую (тайфун) и

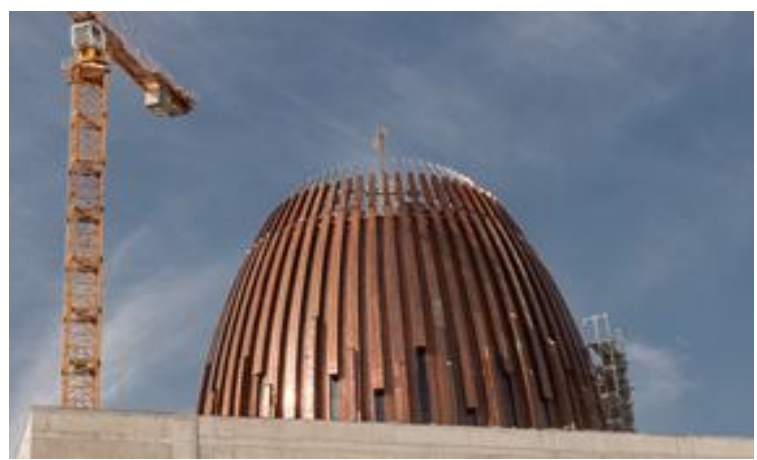

Pис. 7. The dome of the Temple of Divine Providence, Варшава, Польша, 2013 год

тяжелую снеговую нагрузку, и противостоит воздействию соленой воды. 
30 тонн меди ушло на изготовление купола the Temple of Divine Providence, Варшава, Польша (рис. 7). Работа на куполе началась в июне 2012 года и была разделена на несколько этапов. Расчетная долговечность медной крыши - 700 лет с учетом патины, которая будет образовываться на медной поверхности. Медь изменит свой цвет благодаря окислению и через несколько лет поверхность станет зеленого цвета.

Многие считают, что наиболее удобным материалом для изготовления

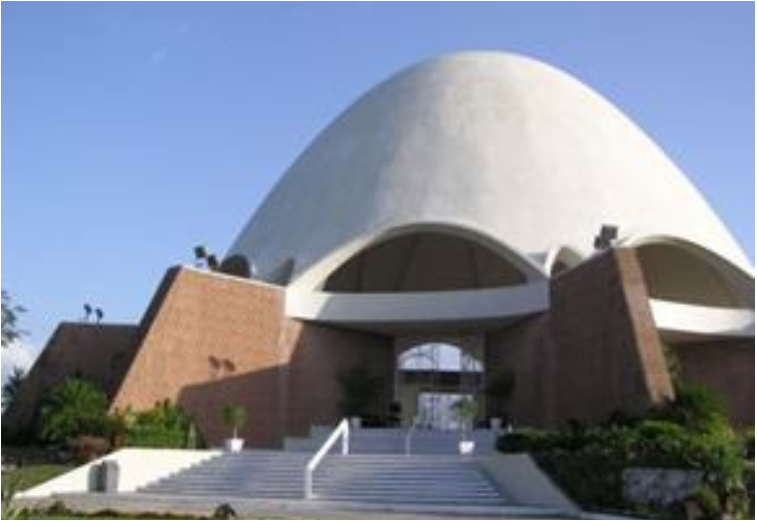

Рис. 8. Bahá'i House of Worship, Panama City, Panama(1972) большеразмерных оболочек в строительстве (рис. 8), является железобетон, как наиболее пластичный материал, которому с помощью опалубки можно придать любую форму. Арматуру малых поперечных сечений легко согнуть согласно кривизне поверхности. Материал оболочки выполняет несущую и ограждающую функции. Тонкостенные железобетонные оболочки обычно применяют для коммерческих зданий, для спортивных сооружений и складов [11]. Тем

не менее, последние 25 лет не строили большепролетные железобетонные купола, в том числе и параболические. Возводились преимущественно сетчатые металлические оболочки.

В основу формы The Bahá'i House of Worship (Tiapapata, Samoa, 1984) был также положен параболоид вращения (рис. 9). 30-метровая купольная структура была запроектирована X. Аманаи (Hossein Amanai).

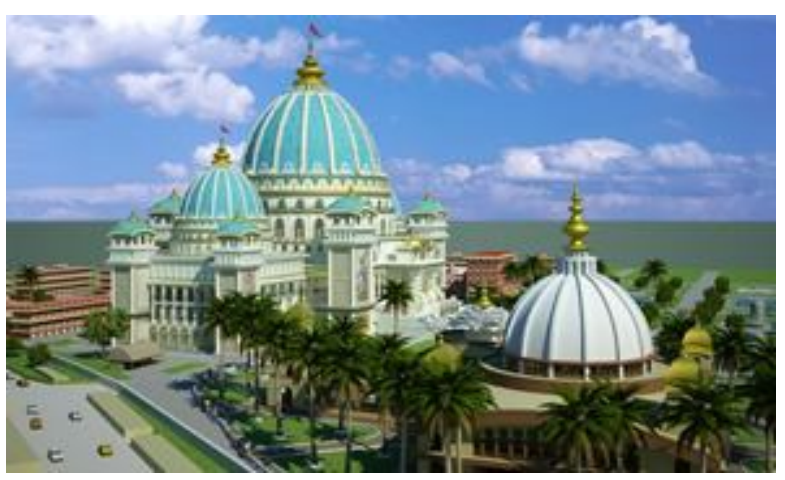

Рис. 10. The Temple of the Vedic Planetarium, Mayapur, India

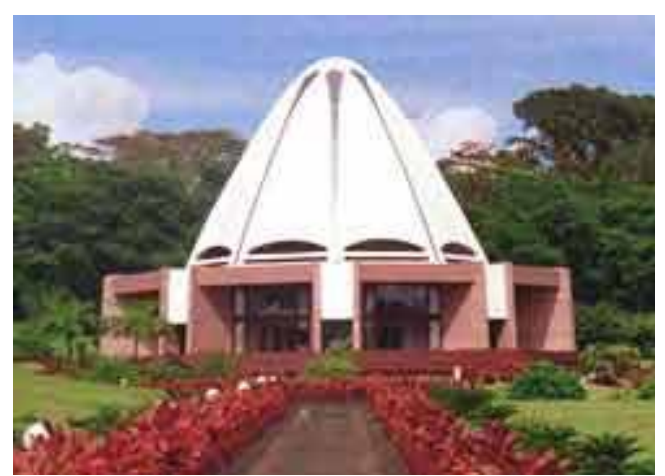

9. The Bahá'i House of Worship, Tiapapata, Samoa

Великолепное бетонное сооружение «The Temple of the Vedic Planetarium» построено в г. Маяпур в Индии (Mayapur, India). Это единственное в мире сооружение, которое совмещает в себе функции храма и планетария (рис. 10). Его купол напоминает купол собора Святого Петра в Риме или купол Капитолия в Вашингтон, но выполнен строго в стиле неоклассической архитектуры Индии. Материал купола специальный бетон и нержавеющая сталь. В строительстве участвовало 50 инженеров, 800 рабочих- строителей из окрестных деревень и 12 проектировщиков. 


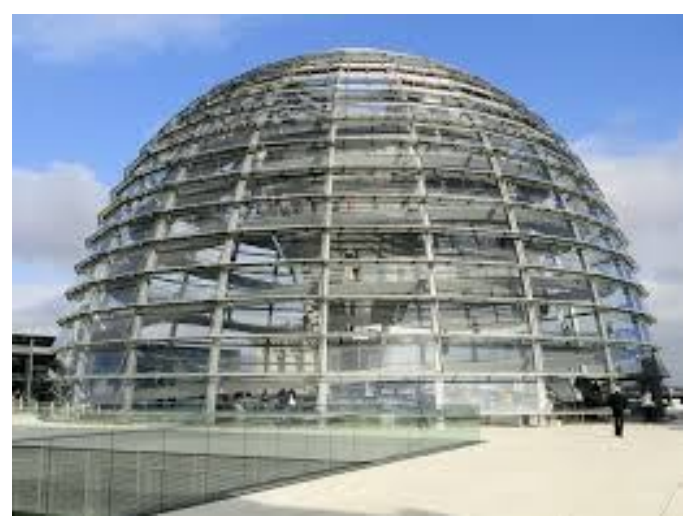

Рис. 11. Купол Рейхстага, Берлин

Стеклянный купол (на металлической сетчатой основе) современного Рейхстага в Берлине (ФРГ) спроектирован архитектором Норманом Фостером в форме близкой к параболоиду вращения, который был возведен наверху реконструированного здания Рейхстага (рис. 11). Один пандус внутри купола предназначен для подъема, другой для спуска. Протяженность спирали - около 230 метров, ширина - около 1,8 метра. Общий вес купола составляет 1200 тонн, а площадь стеклянной поверхности - около 3000 квадратных метров. Рейхстаг был официально открыт после реконструкции 19 апреля 1999 года. За это изящное архитектурноконструктивное решение в 1994 году Н. Фостер был удостоен Притцеровской премии.

Параболический пологий стеклянный купол диаметром 8 м над фойе здания ELF в Libreville (Габон) опирается на 8 колонн круглого поперечного сечения. Ячейки между стальными меридианами и параллелями заполнены стеклами голубого и желтого цвета.
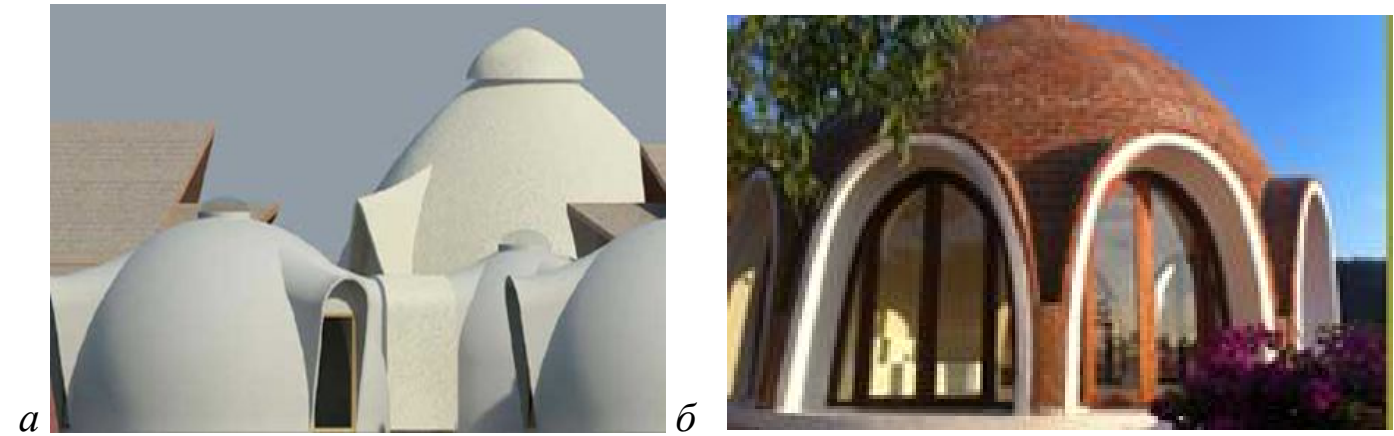

Рис. 12. Жилые параболические купола вращения, Австралия

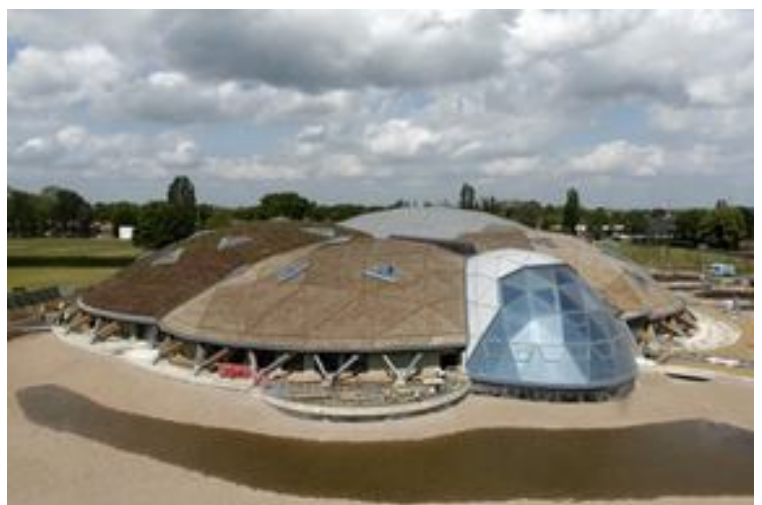

Рис. 13. Проект деревянного сооружения, состоящего из 5 параболоидов вращения

На рис. 12 показаны однокомнатные жилые купола в форме параболоидов вращения для условий Австралии [11]. Материал стенок купола, показанного на рис. 12,a - композит. Купол, представленный на рис. 12, $\sigma$ армирован композитной сеткой (fibre mesh) и выполнен из цемента и песка (армоцемент).

Архитекторы «Leisure Center at Scunthorpe (UK)» создали проект интересного здания, состоящего из 5 параболических куполов (рис. 13). Уникальность этого сооружения состоит в том, что все купола выполнены из различных водостойких материалов, чтобы не выделяться на фоне окружающего паркового ландшафта. Каждый купол защищен от атмосфер- 
ных осадков с использованием системы RENOLIT ALKORPLAN и проект в целом стал крупнейшим геодезическим куполом, выполненном из деревянных конструкций. Этот проект продемонстрировал инновационное использование фанерной мембраны в истории Великобритании.

Глиняные параболические купола (рис. 14), используемые как жилые помещения в сельской местности, являются неотъемлемой частью, народной архитектуры восточной Африки (Камерун). Эти прекрасные сооружения показывают, что уже сотни лет назад местные жители поняли преимущества куполов параболического очертания.

Да и сейчас некоторые фирмы возводят для жилья параболические деревянные купола

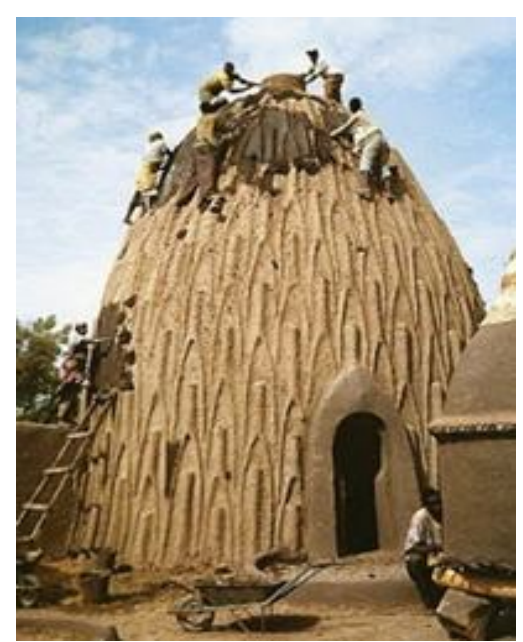

Рис. 14. Глиняный параболический купол (рис. 15). Эти жилые купола пользуются спросом как экологическое жилье.

Во Вьетнаме фирма «Vo Trong Nghia Architects» предлагают к использованию параболоиды вращения из бамбука (рис. 16). Здесь используется народный

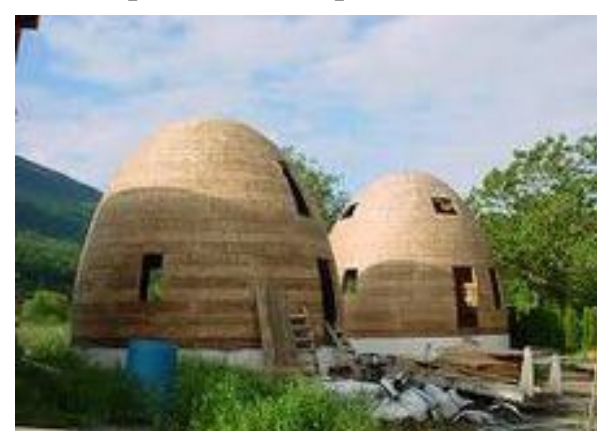

Рис. 15. Параболические жилые однокомнатные деревянные купола

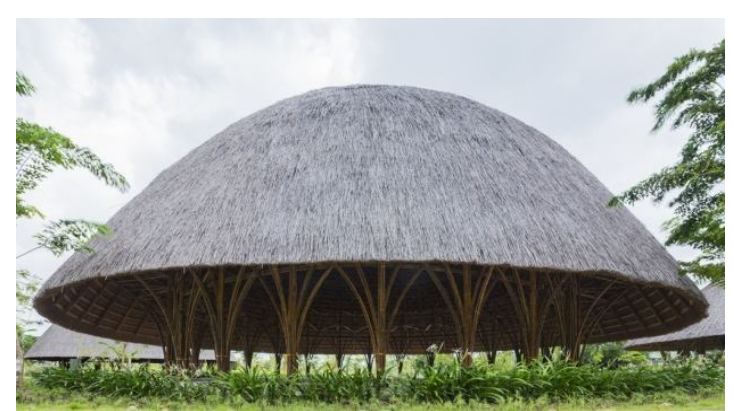

Рис. 16. Общественное здание с параболической бамбуковой крышей

опыт строительства в условиях жаркого климата [12].

Воздухоопорные купола в форме параболоидов вращения нашли применение как складские помещения для хранения медной руды на шахтах Испании

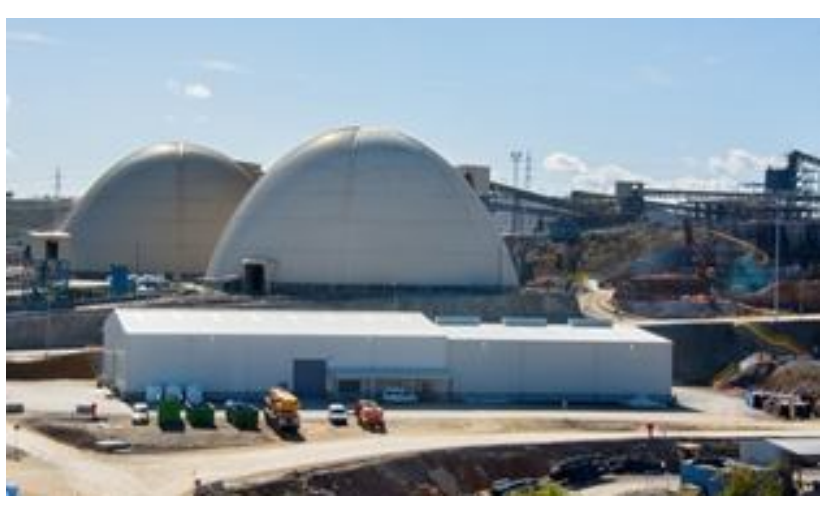

Рис. 17. Воздухоопорные купола [13] (рис. 17) (Minas de Aguas Tenidas, Courtesy Trafigura).

Таким образом, есть железобетонные (рис. 8, 10 ), металлические (рис. 6), стеклянные (рис. 11), глиняные (рис. 14), деревянные (рис. $13,15)$, композитные (полимерные)(рис. 12) [14], прорезиненные (рис. 17) параболические купола в форме параболоида вращения. Но этим не ограничивается применение параболических оболочек вращения. Есть примеры сооружений, где форма параболоида вращения формируется только их меридианами. Например, купол над цирком в г. Екатеринбурге (рис. 18). 
Уникальный несущий внешний купол Екатеринбургского Государственного цирка им. В.И. Филатова в форме параболоида вращения через систему металлических тяг держит внутренний рабочий купол (рис. 18). Цирк открыл свои двери 1 февраля 1980 года. Старое здание цирка сгорело в 1976 году. Теперешнее здание цирка - гордость Урала, т.к. таких конструкций в мире всего две: в Екатеринбурге и в Бразилии.

Только меридианы параболоида вращения и несколь-

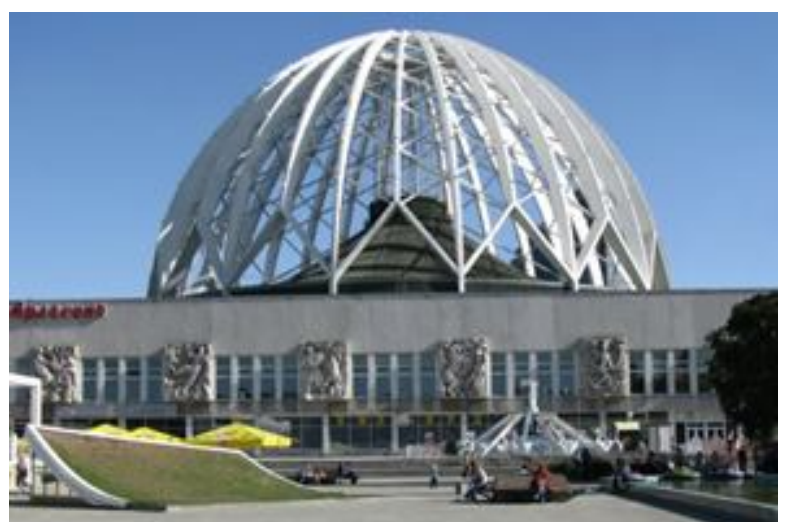

Рис. 18. Екатеринбургский Государственный цирк ко параллелей оставлены на крыше Дворца спорта Цхинвале (Южная Осетия). Авторы - архитекторы считают, что эта кон-

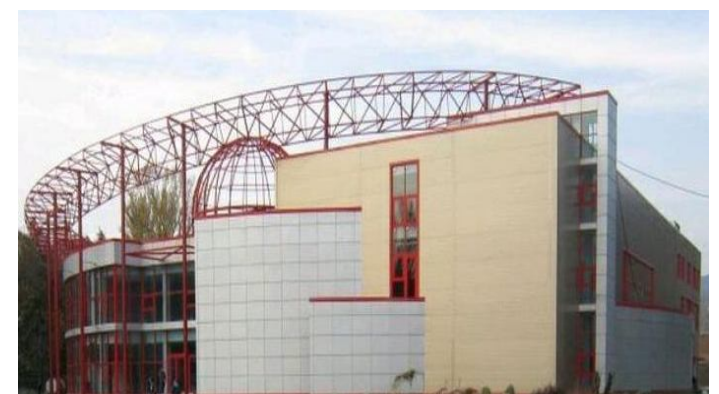

Рис. 19. Дворец спорта в Цхинвале, Юная Осетия

струкция играет важную роль в оформлении целого сооружения (рис. 19).

Manuel Diaz Regueiro [15] реализовал

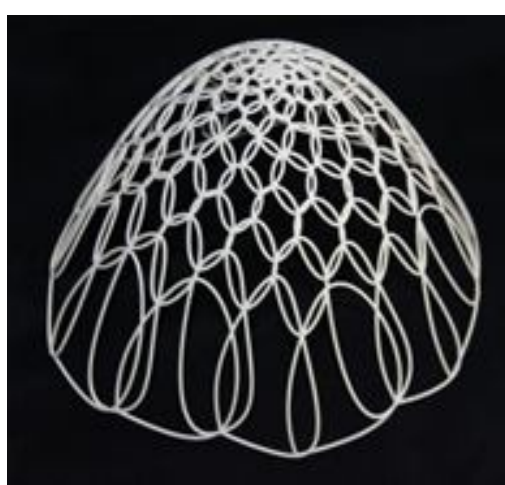

Pис. 20. [15]. Fibonacci-Voronoi Paraboloid Dome

новый способ формирования поверхности параболоида вращения и этот купол он предлагает называть Fibonacci-Voronoi Paraboloid Dome. В 2015 году он создал пластмассовую модель (рис. 20) купола диаметром 26 см и высотой 19 см, Испытания подтвердили прочность и гибкость модели.

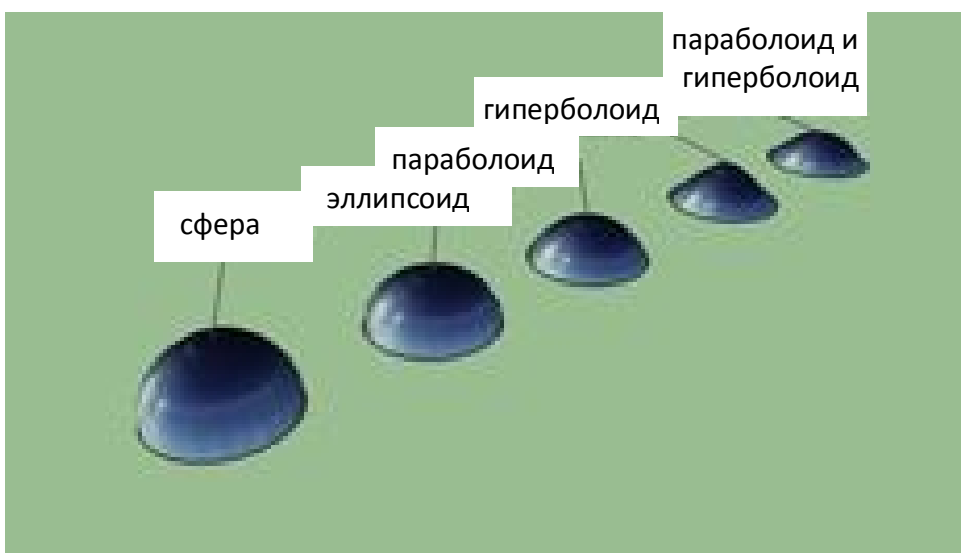

Рис. 21 [16]. 5 основных типов куполов вращения

Стоит обратить внимание на исследования, проведенные с 5 типами куполов (сферические, эллиптические, параболические и гиперболические вращения, а также комбинированные, состоящие из гиперболической поверхности и 
параболической поверхности вращения, рис. 21). Nick B. [16] утверждает, что лучше всего зарекомендовал себя комбинированный купол, составленный внизу

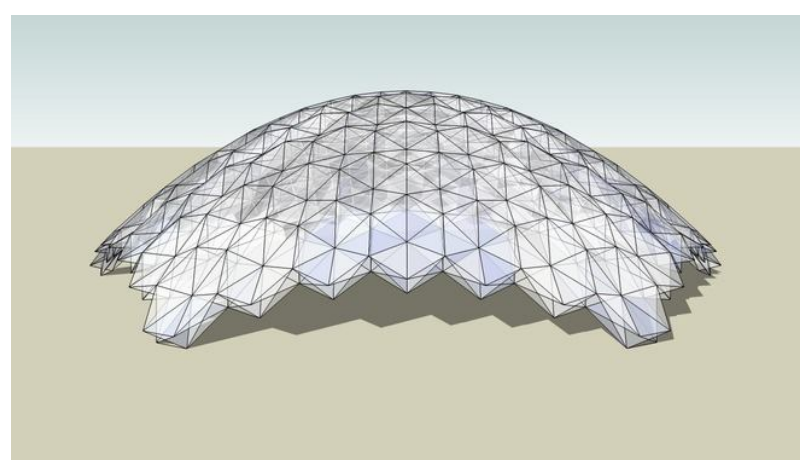

Рис. 22. [16]. Оболочка переноса из гиперболического купола, а вверху - из параболоида вращения.

Как отмечалось в начале статьи, параболоид вращения может быть получен как поверхность переноса одной и той же параболы, одна по другой. Этот способ конструирования продолжает свое развитие в создании купольных структурных регулярных конструкций (рис. 22).

\section{Заключение}

Мы рассмотрели параболические оболочки вращения, применяемые в промышленных, сельскохозяйственных и общественных зданиях, но параболические оболочки широко используются и в ракето- и самолетостроении [17], ракетно- космической технике [18], радио астрономии, в отражателях автомобильных фар [19]. Исследования, проведенные в этих отраслях техники, могут быть полезны и в строительной области.

Интенсивные экспериментальные и теоретические исследования параболических пологих [20] и непологих $[10,21]$ оболочек вращения, проводимые в последнее время, показывают, что они востребованы и практикой, и наукой. Подавляющее число научных исследований и статей, опубликованных в 2000-2017 годах, посвящено изучению собственных колебаний параболических оболочек и динамическим задачам.

$$
\text { С пи сок ли те рат уры }
$$

1. Кривошапко С.Н., Иванов В.Н. Энциклопедия аналитических поверхностей. - М.: Книжный дом «ЛИБРОКОМ», 2010. - 560 с.

2. Krivoshapko S.N., G.L. Gbaguidi Aïssè. Geometry, static, vibration and buckling analysis and applications to thin elliptic paraboloid shells// The Open Construction and Building Technology Journal. - 2016. - 10. - P. 576 - 602.

3. Гмирач К.М., Козлов А.В., Проскуров Р.А. Подбор оптимальных параметров эллипсоидной железобетонной оболочки вращения// Международный научно-исследовательский журнал: технические науки (часть 3). - 2017. - № 2(56).

4. Новожилов В.В. Теория тонких оболочек. - Л.: Судостроение, 1962. - 432 с.

5. Domes: Ancient Rome VS Modern Domes// 16 августа 2013 г., https://sites.google.com/site/furerplox/re/domespokeballsliterally (электронный pecypc).

6. Кривошапко С.Н., Емельянова Ю.В. К вопросу о поверхности вращения с геометрически оптимальной стрелой подъема// Монтажные и специальные работы в строительстве. - 2006. - № 2. - С. $11-14$.

7. Ram Ranjan Sahu and Pramod Kumar Gupta. Blast Diffusion by Different Shapes of Domes// Defense Science Journal. - 2015. - Vol. 65. - No. 1. - P. 77 - 82.

8. Кривошапко С.Н. Параболические оболочки вращения// Монтажные и специальные работы в строительстве. - 1999. - №12. - С. 5 - 12 (библ.: 63 назв.)

9. Abdalla J.A., Mohammed A.S. Dynamic characteristics of large reinforced concrete domes // The 14th World Conference on Earthquake Engineering, October 12-17, 2008, Beijing, China. $-9 \mathrm{p}$.

10. Kang J.-H., Leissa A.W. Free vibration analysis of complete paraboloidal shells of revolution with variable thickness and solid paraboloids from a three-dimensional theory// Computers and Structures. - 2005. - 83, $2594-2608$. 
11. DomeShells Superior Dome Building Systems// Australia, 2017, www.domeshells.com.au (электронный pecypc)

12. Lidija Grozdanic. Mushroom-shaped bamboo pavilions sprout on a Saigon River peninsula, 2015, http://inhabitat.com (электронный ресурс)

13. The National Business, March 24, 2017 (электронный ресурс). $\mathrm{http} / /$ www.thenational.ae/business/economy/mubadala-in-joint-venture-with-trafigura-tooperate-spanish-mines

14. Hobbelman G.J., Timm B., Veer F.A., P.M.J. van Swieten. The design of a full glass dome, using a new glass/polymer composite material// Proceedings LSCE Conference, Warsaw June 2002. -4 p.

15. Manuel Diaz Regueiro. Fibonacci-Voronoi Paraboloid Dome// Mathematical Art Galleries. $-2015 .-2 \mathrm{p}$. cypc).

16. Search for dome// 3D Warehouse, 2017 Trimble Inc., Nederland (Электронный pe-

17. Аврамов К.В., Чернобрывко М.В., Романенко В.Н., Батутина Т.Я., Пирог В.А. Динамическая устойчивость параболических оболочек в сверхзвуковом газовом потоке// Прикладна гідромеханіка. - 2014. -Том 16. - N 4. - С. 3 - 10 (22 назв).

18. Чернобрывко М.В., Аврамов К.В. Собственные колебания параболических оболочек// Мат. методи та фіз.-мех. поля. - 2014. - 57, № 3. - С. 78 - 85 (9 назв.).

19. Steinhaus, H. Mathematical Snapshots, 3rd ed. New York: Dover, 1999.

20. Nilophar Tamboli1, A.B. Kulkarni. Bending Analysis of Paraboloid of Revolution Shell// International Journal of Civil Engineering Research (India). - 2014. - Vol. 5, Nu 4. - P. $307-314$.

21. Omar J. Al-Khatib, George R. Buchanan. Free vibration of a paraboloidal shell of revolution including shear deformation and rotary inertia// Thin-Walled Structures. -2010. Vol. 48, Iss. 3. - P. $223-232$.

Поступила в редакцию 25 марта 2017 г. Прошла рецензирование 18 мая 2017 г. Принята к публикациии 14 июня 2017 г.

\section{Об авторе:}

КРИВОШАПКО СЕРГЕЙ НИКОЛАЕВИЧ родился в 1948 году в г. Волгограде. Окончил Университет дружбы народов им. П. Лумумбы в 1972 г., доктор технических наук (1995 г.), профессор, Российский университет дружбы народов, Инженерная Академия, Департамент Архитектуры и строчтельства. Научные интересы: геометрия и расчет оболочек сложной геометрии, 117198, Москва, ул. Миклухо-Маклая,д.6.Email: sn_krivoshapko@mail.ru

Для цитирования: Кривошапко С.Н. К вопросу о применении параболических оболочек вращения в строительстве в 2000-2017 годах// Строительная механика инженерных конструкций и сооружений. -2017 . - № 4. - С. 4-14 .

DOI: $10.22363 / 1815-5235-2017-4-4-14$

References

1. Krivoshapko, S.N., Ivanov, V.N. (2015). Encyclopedia of Analytical Surfaces. Springer International Publishing Switzerland, $752 \mathrm{p}$.

2. Krivoshapko, S.N., G.L. Gbaguidi Aïssè (2016). Geometry, static, vibration and buckling analysis and applications to thin elliptic paraboloid shells. The Open Construction and Building Technology Journal, (10), $576-602$.

3. Gmirach, K.M., Kozlov, A.V., Proskurov, R.A. (2017). Selection of optimal parameters of elliptical reinforced concrete shell of revolution. Int. Scientific-and-Research Journal: Technical Sciences, Part3, 56(2).

4. Novozhilov, V.V. (1962). Theory of Thin Shells, L.; Sudostroeniye, 432 p.

5. Domes: Ancient Rome VS Modern Domes// August 16, 2013, https://sites.google.com/site/ furerplox/re/domespokeballsliterally.

6. Krivoshapko, S.N., Emel'yanova, Yu.V. (2006). On surfaces of revolution with geometrically optimal rise, Montazhn. $i$ spetsial. raboty v stroitelstve, (2), $11-14$.

7. Ram Ranjan Sahu and Pramod Kumar Gupta. (2015). Blast Diffusion by Different Shapes of Domes. Defense Science Journal, 65(1), 77 - 82.

8. Krivoshapko, S.N. (1999). Parabolic shells of revolution, Montazhn. i spetsial. raboty $v$ stroitelstve, (12), 5 - 12 (63 refs)

9. Abdalla, J.A., Mohammed, A.S. (2008). Dynamic characteristics of large reinforced concrete domes. The 14th World Conference on Earthquake Engineering, Oct. 12-17, 2008, Beijing, China, 9 p. 
10. Kang, J.-H., Leissa, A.W. (2005). Free vibration analysis of complete paraboloidal shells of revolution with variable thickness and solid paraboloids from a three-dimensional theory. Computers and Structures, p. $2594-2608$.

11. DomeShells Superior Dome Building Systems// Australia, 2017, www.domeshells.com.au (электронный ресурс)

12. Lidija Grozdanic (2015). Mushroom-shaped bamboo pavilions sprout on a Saigon River peninsula, http://inhabitat.com

13. The National Business, March 24, 2017, ttp:/www.thenational.ae/business/economy/mubadalain-joint-venture-with-trafigura-to-operate-spanish-mines.

14. Hobbelman, G.J., Timm, B., Veer, F.A., P.M.J. van Swieten (2002). The design of a full glass dome, using a new glass/polymer composite material. Proceedings LSCE Conference, Warsaw, June 2002, 4 p.

15. Manuel Diaz Regueiro (2015). Fibonacci-Voronoi Paraboloid Dome, Mathematical Art Galleries, $2 \mathrm{p}$.

16. Search for dome// 3D Warehouse, 2017 Trimble Inc., Nederland.

17. Avramov, K.V., Chernobryvko, M.V., Romanenko, V.N., Batutina, T.Ya., Pirog, V.A. (2014). Dynamical stability of parabolic shells in super sound gas stream, Prikladna Gidromehanica [Applied Hydromechanics], 16(4), $3-10$ (22 refs).

18. Chernobryvko, M.V., Avramov, K.V. (2014). Natural vibration of parabolic shells, Mat. Metodi ta phiz.-meh. pollya, 57(3), $78-85$ (9 refs).

19. Steinhaus, H.(1999). Mathematical Snapshots, 3rd ed. New York: Dover.

20. Nilophar Tamboli1, A.B. Kulkarni. (2014). Bending Analysis of Paraboloid of Revolution Shell, International Journal of Civil Engineering Research (India), 5(4), 307 - 314.

21. Omar J. Al-Khatib, George R. Buchanan. (2010). Free vibration of a paraboloidal shell of revolution including shear deformation and rotary inertia, Thin-Walled Structures, 48 (3), $223-232$.

\section{ON APPLICATION OF PARABOLIC SHELLS OF REVOLUTION IN CIVIL ENGINEERING IN 2000-2017}

\section{S.N. KRIVOSHAPKO \\ Peoples' Friendship University of Russia (RUDN University), Moscow, Russia}

Dome is often used by architects for cover of large spans. Only spherical, conical, elliptical, parabolic, and hyperbolic surfaces of revolution among tens of the well-known surfaces of revolution can be taken for middle surfaces of domes. Spherical domes have the most spread in modern building due to simplicity of their form in comparison with other shells of double curvature. But researches of paraboloidal domes do not end. Some new information on strength analysis of parabolic shells, on determination of the frequencies of their natural vibrations and the examples of application of paraboloid of revolution in civil engineering in $1900=2017$ are presented in this review paper.

The main presented bibliography was published in XXI century.

Key words: paraboloid of revolution, parabolic dome of revolution, examples of application of parab0oloid of revolution.

\section{Article history:}

Received: March 25, 2017. Revised: May 18, 2017. Accepted: June 14, 2017.

\section{About the authors:}

KRIVOSHAPKO SERGEY NIKOLAEVICH was born in Volgograd (Russia) in 1948. He graduated Peoples' Friendship University named after P. Lumumba in 1972, ScD (1995), Professor, RUDN University, Engineering Academia, Department of Architecture and Building. Scientific interests: Geometry and strength analysis of shells of complex geometry. 6 Miklukho-Maklaya Str., Moscow, 117198, Russian Federation. Email: sn_krivoshapko@mail.ru

\section{For citation:}

Krivoshapko S.N. (2017). On application of parabolic shells of revolution in civil engineering in 2000-2017. Structural Mechanics of Engineering Constructions and Buildings, (4), 4 - 14,

DOI: $10.22363 / 1815-5235-2017-4-4-14$ 